\title{
O Estadão e as eleições: análise da campanha presidencial de 1945 com base na leitura do jornal O Estado de S. Paulo
}

\author{
The Newspaper $O$ Estado de S. Paulo and elections: an analysis of \\ presidential campaign in 1945 based on reading the newspaper $O$ \\ Estado de S. Paulo
}

\author{
J eovane Aparecido Amorim*
}

RESUMO

O objetivo deste artigo é analisar a campanha presidencial de 1945, bem como o comportamento do jornal O Estado de S. Paulo em relação a este movimento político que aconteceu em 1945 em virtude do processo de redemocratização, que culminou com a eleição presidencial, em dezembro daquele ano. As principais questões abordadas neste trabalho serão: a tentativa de construção da imagem do General Eurico Gaspar Dutra por parte do jornal, a fim de mostra-lo como cidadão apto para conduzir o país, além do surgimento do movimento Queremista e a sua influência no decorrer da campanha, e o como o jornal se posicionou em relação ao Partido Trabalhista Brasileiro (PTB) do Estado do Paraná, tentando identificar a candidatura de Dutra com os trabalhadores, que naquele momento eram uma força política de grande importância que poderia mudar os rumos das eleições.

Palavras Chave: O Estado de S. Paulo. Eleições. Eurico Gaspar Dutra. Partido Trabalhista Brasileiro. O Estado do Paraná.
ABSTRACT

The objective of this paper is to analyze the presidential campaign of 1945, and the behavior of the newspaper O Estado de S. Paulo in relation to this political movement that happened in 1945 because of the democratization process, which culminated with the presidential election in December that year. The main questions addressed in this work are: the attempt to build the image of General Eurico Gaspar Dutra by the newspaper, in order to present him as a citizen able to lead the country, the appearance of Queremista movement and its influence throughout the campaign, and as how the newspaper positioned itself in relation to the Brazilian Labor Party (PTB) of Paraná State, trying to identify Dutra's candidacy with the workers, who then were a major political force in that moment that could change the course of elections.

KEY WORDS. The newspaper O Estado of S. Paulo. Elections. Eurico Gaspar Dutra. Brazilian Labor Party. The state of Paraná.

As eleições presidenciais de 1945 foram de grande importância para o processo democrático brasileiro, pois marcaram o retorno da democracia depois de quase sete anos de ditadura estadonovista. Portanto este artigo busca compreender como a campanha do General Eurico Gaspar Dutra buscou arregimentar apoio da massa trabalhadora uma vez que os trabalhadores configuravam o surgimento de força política grande importância, destacando o PTB (Partido Trabalhista Brasileiro), que

\footnotetext{
* Possui Licenciatura em História pela Universidade Estadual de Londrina, Professor de ensino fundamental na rede particuar de ensino.
} 
estava empenhado na manutenção do presidente Getúlio Vargas, além de compreender como o jornal O Estado de S. Paulo se posicionou quanto ao pleito presidencial de 1945, apresentando sua posição partidária no curso dos meses de março a setembro, bem como a busca por apoio do PTB para a candidatura de Eurico Gaspar Dutra, elucidando como o uso da imagem do PTB paranaense que havia aderido à candidatura de Dutra em nível estadual, uma vez que o PTB, em nível nacional, ainda não havia declarado seu apoio, esperando a decisão de Vargas quanto a ser ou não ser candidato.

Com a crise do Estado Novo, o Brasil começou a viver uma nova cena política que tornou possível a reorganização partidária, além do surgimento de manifestações anti estadonovistas. Assim, em final de 1944, o Estado Novo estava próximo de seu fim, como o próprio Vargas declarou em 31 de dezembro de 1944, no tradicional banquete de passagem de ano, oferecido pelas Forças Armadas. Segundo Gomes e D’Áraujo (1989, p. 11), “Getúlio anunciava oficialmente à nação a breve execução da reforma constitucional, necessária para a igualmente breve realização de eleições que reconduziriam o país à normalidade democrática".

Em março, o recém-empossado Ministro J ustiça o pernambucano Agamenon Magalhães, foi incumbido de coordenar o processo de redemocratização, com a promulgação da Lei Constitucional no 9, de 1945, fixando o prazo de 90 dias para que fossem realizadas eleições. No dia 9 de março, Agamenon instalou uma comissão para elaboração do novo Código Eleitoral. Segundo Gomes (1989, p. 13),

Quando esta se reuniu pela primeira vez, Agamenon transmitiu-lhe uma orientação básica conformada em cinco pontos, entre os quais estava a adoção do alistamento simples e ex-officio. Os demais eram: o voto secreto; justiça eleitoral autônoma; apuração rápida e imediata e partidos nacionais.

Destas observações podemos notar algumas diretrizes que eram influências do Estado Novo e como Agamenon procurou implementá-las. A primeira delas foi o alistamento simples e ex-officio que era "um procedimento que possibilitara a inscrição eleitoral em blocos de pessoas que pertencentes a organizações, como sindicatos, institutos previdenciários e outras associações (ou agremiações?)” (GOMES, 1989, p.12), além de permitir que os sindicatos organizados pelo Ministério do Trabalho, durante a gestão de Marcondes Filho², concorressem às eleições, o que possibilitava ainda a candidatura de Getúlio Vargas à presidência da República.

\footnotetext{
2 Marcondes Filho ocupou a pasta de ministro do trabalho de 29/12/ 1941 a 29/10/1945, com o objetivo de organizar os sindicatos e formar lideranças.
} 
Em meados do ano de 1945, surgiu em cena uma manifestação de cunho popular chamada de Queremismo, possuindo por bandeira a candidatura de Getúlio Vargas à presidência ou ainda a busca por uma "constituinte com Getúlio" o que, na visão dos participantes e, conforme a propaganda do Ministério do Trabalho³, seria a garantia da manutenção dos benefícios "recebidos" a partir de 1930, e de que Vargas representava, em última instância, estes benefícios. Nas palavras de Ferreira (2005, p. 25),

Entre fins de fevereiro de 1945 [...] e 29 de outubro, com a deposição de Vargas, a sociedade brasileira, em pleno processo de democratização política, mobilizada em dois campos antagônicos, assistiu e participou de um movimento de massa, de proporções grandiosas, conhecido como queremismo.

A participação do Departamento de Imprensa e Propaganda - DIP e do Mistério do trabalho é evidente, fazendo com que o movimento, que possuía apenas corpo, ganhasse também uma "cabeça” política. Porém, os trabalhadores eram as bases desse movimento, que se tornou mais forte entre os meses de julho a agosto, quando as manifestações ganharam as ruas, e o movimento Queremista já não podia mais ser visto apenas como uma onda formada por arruaceiros que pretendiam a permanência de Vargas. Com as diretrizes de organização, o Queremismo tornou-se um movimento político.

As mudanças de julho para agosto, portanto, são significativas. Da simples personalização da política passou a reconhecer a necessidade da própria institucionalização da política, por meio de uma Assembléia Nacional Constituinte. (FERREIRA, 2005, p.52).

Entretanto, para que Getúlio pudesse concorrer às eleições era preciso que ele se desincompatibilizasse do cargo, o que não ocorreu. Dessa forma, "com grande frustração, os queremistas chegaram no dia 3 de setembro sem verem Vargas se desincompatibilizar do cargo. Definitivamente, ele não seria candidato". (FERREIRA, 2005, p.52).

A disputa então polarizou-se entre dois partidos: A União Democrática Nacional (UDN), com o Brigadeiro Eduardo Gomes (UDN) e o Partido Social Democrático (PSD) com o General Eurico Gaspar Dutra (PSD), este último era considerado candidato do governo, uma vez que grande parte do PSD era proveniente dos quadros do Governo.

\footnotetext{
3 Aqui me refiro às propagandas relacionadas ao mundo do trabalho e que o Ministério do Trabalho disseminou durante o Estado Novo, como um presente que o próprio presidente Getúlio Vargas concedera aos trabalhadores. Sobre o assunto procurar Gomes (1988, p. 189-329).
} 
Para compreender a trajetória de Dutra é preciso conhecer alguns aspectos de sua história. O General Eurico Gaspar Dutra nasceu em Cuiabá em 1883, ingressou na Escola Militar da Praia Vermelha, no Rio de Janeiro, em 1904. No mesmo ano participou da repressão da Revolta da vacina. Em 1902 ingressou na Escola preparatória e Tática de Rio Pardo, onde foi colega do então cadete Getúlio Dorneles Vargas.

Durante os levantes tenentistas Dutra os combateu, em 1930 foi convidado a participar da Revolução de 1930, convite que ele recusou. A aproximação com Vargas veio com a repressão ao Movimento Constitucionalista de 1932. Em 1936 foi nomeado ministro da Guerra e ajudou a articular o Golpe do Estado Novo, tornando-se um dos homens fortes do regime.

No início da Segunda Guerra, Dutra era a favor do alinhamento com a Alemanha, o que não se concretizou. Contudo, após o alinhamento do Brasil com EUA foi Dutra quem conduziu o processo de organização e participação da FEB (Força Expedicionária Brasileira) no conflito. Com o fim do regime, Dutra foi nomeado pelo PSD como candidato à presidência da República.

Como foi dito, para a realização deste trabalho, utilizei, como fonte documental, o jornal O Estado de S. Paulo (OESP), sendo necessário situar, ainda que brevemente, este veículo e sua história: O OESP surgiu durante o Império, lançado no dia 4 de janeiro de 1875, sob o nome de A Província de S. Paulo, e somente em janeiro de 1890, depois de proclamada República e feita à alteração dos nomes das unidades federativas, é que começou a circular com o seu nome atual.

De acordo com Capelato e Prado, o jornal possuía claras ideias do seu objetivo “a permanente e sempre reiterada preocupação política do jornal de - para além de sua função informativa - se apresentar como 'órgão modelador de opinião publica'”' (CAPELATO; PRADO, 1980, p. xix).

O jornal foi fundado por 16 sócios, com objetivo a criação de um veículo de imprensa republicana. Em 1902, Júlio de Mesquita tornou-se o único proprietário do diário. Durante sua administração, o OESP colocou-se como um defensor de ideias liberais ${ }^{4}$, realizando sistemática oposição aos governos federais e estaduais. Segundo Capelato (1989, p. 12):

Na década de 20 fortaleceu-se em São Paulo um movimento de oposição ao governo da Primeira República. Setores liberais atuaram através da imprensa, educação e partidos, procurando nesses campos, produzir novas elites dirigentes e formar a consciência nacional.

\footnotetext{
4 Sobre a ideologia liberal Ver: Capelato (1989).
} 
Mesmo sendo defensor do liberalismo e crítico dos governos constituídos, o jornal não se declarava como órgão de nenhum partido político:

Júlio de Mesquita, mesmo enquanto membro atuante do PRP, recusou a ideia de transformá-lo em órgão do partido, fato que se repetiu quando da criação do Partido Democrático, agremiação a que deu seu apoio, sem consentir, entretanto que "OESP" se tornasse seu órgão oficial [...] consideravam que a não vinculação aos governos e partidos lhes permitia exercer livremente, o papel de críticos da situação vigente, na crença de que nas democracias 'a imprensa é o único tribunal capaz de chamar a contas os governos que abusam' (9-101929). (CAPELATO; PRADO, 1980, p.24).

Descontentes com os rumos políticos do Brasil, os diretores do OESP viram na Aliança Liberal uma oportunidade de quebra da política dos governadores ${ }^{5}$ e a implementação de um governo que prezasse pelos ideais liberais ${ }^{6}$, além da moralização da política nacional. Para tal "o ESP apoiou o movimento e foi favorável à chapa Getúlio Vargas/J oão Pessoa". (CAPELATO; PRADO, 1980, p.35). Em São Paulo, além desse jornal, a Aliança Liberal possuía apoio do Partido Democrático (PD) que era oposição ao Partido Republicano Paulista (PRP).

Com a derrota de Vargas e a morte de J oão Pessoa a "Revolução" eclodiu e os representantes do jornal a consideraram como uma opção para reestabelecer a ordem e a moralidade política. Com a vitória, a "Revolução de 1930" entregou o poder do Executivo a Vargas, tendo início o Governo Provisório. O OESP continuou a apoiá-lo:

A situação pós-revolucionária inspirava cuidados, e os liberais temiam que as dificuldades econômicas pudessem agravar o problema social. Diante desse quadro, o OESP apostou na política de Vargas, esperando que ela pusesse freios aos conflitos. (CAPELATO; PRADO, 1980, p.109).

O alinhamento político entre o OESP e o Governo Provisório teve vida efêmera, pois Vargas nomeou um interventor militar e não paulista, para o governo de São Paulo, o que fez com que o PD passasse a ser crítico do Governo, sob a alegação de traição, como podemos ver na análise de Capelato e Prado:

\footnotetext{
${ }^{5}$ Aqui me refiro ao controle exercido por São Paulo e Minas Gerais nas eleições presidenciais, já que os dois estados possuíam eram os dois maiores colégios eleitorais do país.

${ }^{6}$ De acordo com Capelato e Prado "de conformidade com esses princípios, o papel do Estado se resume a promover a liberdade, a igualdade, a justiça,a segurança, o gozo da propriedade e outros objetivos individuais. Um governo responsável, na concepção desses liberais, deveria objetivar a manutenção de uma sociedade em que a capacidade e a energia de cada individuo fossem a chave para o poder e a riqueza" (CAPELATO, 1980, p. 92).
} 
Após a vitória da Revolução, o governo foi confiado a um interventor militar - J oão Alberto - com o que muito se ressentiu o PD, pois em acordo preliminar com Getúlio Vargas, ficara acertado que a direção de São Paulo seria entregue a Francisco Morat. Dessa maneira, a revolução já começava, para o PD sob signo de traição (CAPELATO; PRADO, 1980, p.40).

Mesmo com esta nomeação, o OESP não se tornou crítico de imediato, pois acreditava que essa situação seria transitória e, além do mais, o Interventor procurou aproximar-se de pessoas ligadas tanto ao PD quanto ao periódico, como podemos notar, ainda segundo Capelato e Prado (1980, p. 41):

\begin{abstract}
O ESP não manifestou seu descontentamento por acreditar que essa medida seria transitória. Além disso, a constituição do primeiro secretariado amenizou suas apreensões, pois J oão Alberto chamara para integrar seu governo elementos de confiança do jornal: Plínio Barreto, então redator chefe de "O ESP" foi designado a ocupar o cargo de secretário da Justiça [...] por estas circunstancias, o jornal acatou favoravelmente os primeiros atos do interventor. Entretanto, logo após a renúncia desse primeiro secretário, surgiram nas páginas de 'O ESP' os primeiros sinais de oposição que iria culminar no levante de 1932.
\end{abstract}

Descontente com a política do Governo provisório, o jornal começou a realizar oposição, pois "no início de 1931, já era visível a decepção do jornal com o movimento revolucionário que vinha representado a negação de seu projeto político". (CAPELATO; PRADO, 1980, p.42).

A decepção em relação à política estadual e federal fez com que o jornal se posicionasse em favor da "Revolução Constitucionalista de 1932" e apoiasse a luta armada, porém, a vitória não veio e o movimento foi reprimido pelas forças federais em apenas quatro meses de resistência. Julio de Mesquita Filho, agora proprietário7, foi exilado, retornando ao país no ano seguinte.

Em 1935 o "perigo comunista" serviu de argumento para que o OESP apoiasse as medidas adotadas por Vargas, pois era preferível um Executivo forte e que defendesse os interesses da propriedade, do que um governo comunista que iria totalmente contra os interesses seus interesses liberais.

O periódico sempre se colocou como uns dos maiores críticos do fortalecimento dos governos de Washington Luis e Arthur Bernardes, por outro lado, em face à ameaça do comunismo, não considerou uma agressão a centralização do poder, pois o fortalecimento do Governo era visto como necessário. Dessa forma, “ $\mathrm{O}$ ESP nunca levantou a voz contra qualquer ato menos recomendável do governo; muito

\footnotetext{
7 Em 1927J ulio de Mesquita faleceu, deixando o jornal para J ulio de Mesquita Filho.
} 
pelo contrário, considerava a lei de segurança nacional insuficiente" (CAPELATO; PRADO, 1980, p. 58).

O jornal apoiava as medidas adotadas pelo governo, provavelmente por acreditar que este estaria no fim, pois as eleições estavam programadas para 1938. Para aquele pleito, o periódico já apoiava a pré-candidatura de Armando de Sales Oliveira, que renunciou ao cargo de interventor para concorrer nas eleições presidenciais.

Para o OESP, Armando de Sales Oliveira era o candidato ideal, pois também seguia os ideais liberais defendidos pelo periódico. Contudo, as pretensões do veículo foram arruinadas pelo golpe de 10 de novembro de 1937, que instaurou o Estado Novo e, segundo Capelato e Prado (1980, p. 65):

\begin{abstract}
Desta forma ruíam silenciosamente as pretensões de "O ESP" de levar ao poder, pela primeira vez um candidato cujo programa político traduzisse seu pensamento. Após o Golpe, evidentemente, a censura coibiu qualquer manifestação contrária ao novo estado de coisas por parte da imprensa. Armando de Sales de Oliveira foi confinado em Minas gerais, seguindo depois para o exílio no exterior).
\end{abstract}

A liberdade de imprensa foi reprimida durante o Estado Novo e o DIP realizou o controle da Imprensa. Esse controle era tamanho que o Departamento chegou a expropriar o jornal. Segundo a explicação de Capelato (1989, p.27):

Em março de 1940, a redação do OESP foi ocupada pela polícia militar sob alegação de que ali havia armas escondidas. O jornal foi tomado, para logo depois reaparecer subordinado ao DIP, dirigido por Abner Mourão, antigo diretor de o Correio Paulistano

Assim o jornal, durante os anos de 1926 a 1937, viveu momentos de ambiguidade, nunca vendo seus ideais liberais alcançarem o governo do país, além de oscilar no apoio às medidas governamentais, principalmente após 1930. Julio de Mesquita Filho continuou a se opor ao regime instaurado e logo foi exilado, perdendo o controle de seu jornal em 1940 e permanecendo assim até dezembro de 1945, quando o pleito presidencial já estava finalizado.

Desta forma o texto procura apresentar qual era a visão, que os diretores imprimiram no jornal OESP, e como estes se manifestavam em relação à campanha presidencial de 1945 e busca responder algumas questões: Como o OESP apresenta Dutra aos seus leitores? Que estratégia usou para construir uma imagem mais popular da figura de Dutra para atrair o voto dos trabalhadores? Como o jornal se relacionou com Queremismo? 


\section{A Tentativa de Construção do Mito Dutra Pelo J ornal O Estado de S. Paulo}

Com a instauração do Estado Novo, a imprensa do país foi especialmente controlada pelo DIP. Os oposicionistas foram duramente censurados fato que não ocorrera na Revolução Constitucionalista de 1932, pois, segundo Capelato, "Após a derrota do movimento, os jornais paulistas não foram impedidos de circular, prosseguindo normalmente em suas atividades". (CAPELATO, 1989, p. 27).

Porém, com o golpe de 10 de novembro 1937 a repressão abateu-se sobre a imprensa e, diferentemente do que ocorrera em 1930 e 1932, impediu-se "a livre manifestação dos órgãos de imprensa durante todo o período da ditadura" (CAPELATO, 1989, p. 27).

No caso do jornal de Julio de Mesquita Filho, a censura foi mais severa, chegando a expropriá-lo, em março de 1940, sendo interessante notar, entretanto, que o OESP não foi empastelado ${ }^{8}$. Essa medida pode-se dever ao fato deste periódico ser um dos mais importantes do país e, a partir de 1940, ele, que fora de oposição desde a Revolução Constitucionalista, passaria, sob intervenção, a endossar a lista dos jornais pró Estado Novo.

Contudo, este período foi renegado na história do jornal e isso pode ser confirmado na leitura de seu website que noticia a comemoração, em 1975, dos 100 anos de sua existência, da seguinte forma: "No ano seguinte, no dia 4 de janeiro o jornal "O Estado de S. Paulo" completou 100 anos de existência e comemorou apenas 95 de vida, ignorando os cinco anos em que foi dirigido pela ditadura de Getúlio Vargas (1940-45)"9.

Logo depois da expropriação, o jornal voltou a circular, tendo Abner Mourão como diretor de redação nomeado pelo DIP. Desta forma, o jornal passou a ser um dos meios de comunicação do Estado Novo.

Com o enfraquecimento do Estado Novo, as manifestações políticas tornam-se mais intensas, seja pela oposição, na figura da UDN, seja na situação com PSD e PTB. Durante o processo no qual Vargas anunciou que iria encaminhar o país à redemocratização, no dia 24 de fevereiro de 1945, pela primeira vez vê-se, no OESP, alguma notícia acerca dos movimentos políticos nacionais, com o seguinte título "o primeiro e decisivo passo". No dia 27 de fevereiro de 1945 foi publicada, pela primeira vez, a seção que embasa a análise das discussões que realizarei de agora em diante, intitulada "a Situação Política”.

8 O empastelamento consistia em quebrar todo o maquinário do jornal.

9 Disponível em: http://www.estadao.com.br/historico/print/resumo.htm. 
Assim, no dia 27 fevereiro de 1945, a Situação Política republica um artigo do jornal A Manhã, de 30 de julho de 1942, contendo um discurso de Oswaldo Aranha, abordando questões sobre o Estado Novo e, antes do artigo de Aranha, o editor, enfatiza sua importância: "pela grande oportunidade de suas afirmações, que valem como excelente resposta a certas interpretações increpações [sic] do momento, é com especial apreço que A Manhã os republica hoje Ei-las"” (OESP, 27/ 02/ 1945).

No artigo, Aranha abordou questões como, "as grandes conquistas do regime", "a verdadeira democracia”, "os grandes momentos nacionais não saíram das urnas”, "a própria república não foi uma vitória eleitoral", "o presidente ao lado dos grandes vultos da história". Isto vinha contribuir para o prestígio de Vargas, lembrando que ele não devia ser deixado de lado, até mesmo porque o jornal ainda era gerido pelos mesmos que foram empossados nos cargos pelo DIP, ou seja, o OESP ainda era um veículo de imprensa vinculado ao Estado Novo, sendo interessante perceber que Oswaldo Aranha já havia deixado o Governo, e estava alinhado com a UDN, mas seu discurso foi muito bem utilizado pelo DIP em favor do já enfraquecido Estado Novo, interessante notar que não mencionada a informação da saída de Aranha do Governo.

O que abordarei daqui em diante será a tentativa de construção do mito Dutra nas páginas do OESP, pois até aqui a busca pela valorização do Estado Novo aconteceu principalmente por meio do discurso de Aranha, mas, segundo o OESP, Dutra iria dar continuidade às políticas estadonovistas, só que agora a democracia seria o "carro chefe".

O diretor do OESP, Abner Mourão, era integrante do PSD e isto pode demonstrar em que medida o jornal foi colocado à disposição do candidato Eurico Gaspar Dutra e do seu partido. Isto pode ser confirmado, pois no dia 09 março de 1945, pela primeira vez, a seção a Situação Política falou sobre Dutra, sendo até o dia 03 de setembro de 1945 (data limite desta pesquisa), o seu nome abordado em 109 editoriais, salientando-se que em momento algum o nome Dutra foi negativamente citado ou questionado no jornal, pelo contrário, sendo em geral extremamente elogiado.

A imagem de Dutra começou a ser construída pelo jornal em um artigo escrito por Vinicius da Veiga, que não se encontra na Situação Política, mas que se inclui aqui por se tratar de um artigo que possui claros objetivos de veiculação de uma imagem heróica de Dutra. O artigo intitulado "o General Eurico Dutra - símbolo e programa de uma epoca" (OESP, 09/ 03/ 1945).

Neste editorial o autor fala da grandeza de Dutra, nas lutas travadas pelo Brasil e da preocupação com os soldados brasileiros, e afirma: 
O General Eurico Dutra é um homem acostumado a meditação e disciplina, ao contrario de certos ex-ministros e demagogos, e só permitiu que os brasileiros enfrentassem a luta, depois de treinados materialmente para ela, e, também, depois, de terem gravada no cérebro e no coração, bem nítida, a razão de nossa entrada no conflito, ou seja, a necessidade de integrar o Brasil, não meramente na comunhão platonica das nações, e que é fácil prometer nas Conferencias Internacionais (OESP, 09/03/45).

Em outro ponto da reportagem havia quase um anúncio da pré-candidatura de Dutra, no qual se lia:

O Exército, como ainda dentro em breve testemunhará, pela sua palavra ansiosamente esperada, o General Dutra não é um perigo para a democracia. O perigos que possivelmente a ameaçam estão, creio eu, com aqueles que se proclamam, a todo pretexto, rebentos das fileiras do povo e sabem falar a ele com a boca adocicada pelo mel de uma linguagem falsa, baseada na inspiração criativa do medo e da desconfiança, que geram germes de monstros e material em todos escaninhos da alma e do corpo da nação. O Exercito não. Dele só podemos esperar garantias e segurança e absoluta neutralidade diante dos debates políticos pelos nossos direitos constitucionais e estabilização de um poder legitimo no futuro (OESP, 09/03/45).

Não se pode esquecer o fato de Dutra ser o Ministro da Guerra e de o Brasil ainda estar em Guerra, assim, todo este apelo que o artigo faz a Dutra, o coloca como defensor da democracia na Guerra, e dentro do país. A seção apresenta Dutra como uma figura que possui todas as condições de manter a democracia e a constitucionalidade do país, assim sendo, o anúncio formal de sua candidatura não vai demorar muito a acontecer.

No dia 14 de março de 1945, na capa do jornal, que geralmente era ocupada por notícias da Guerra, apareceu uma reportagem com a seguinte manchete "Lançada por São Paulo e Minas Gerais a Candidatura do General Eurico Gaspar Dutra à Presidência da República". Dizia a reportagem sobre o apoio recebido por Dutra: "foi subscrita pelo Sr. Fernando Costa $^{10}$, Benedito Valadares ${ }^{11}$ e as mais expressivas figuras do cenário político e das forças produtoras do Estado”. Ou seja, os interventores estaduais de São Paulo e Minas apresentavam a candidatura Dutra como sendo bastante prestigiada, ressaltando-se o fato de que estes continuavam sendo os dois estados da Federação com os maiores colégios eleitorais ${ }^{12}$.

O editorial ainda afirmava que: "há muito que não se registrava na história do Brasil um acontecimento de tão transcendental importância política como a reunião

10 Interventor de São Paulo.

11 Interventor de Minas Gerais

12 Aqui me refiro ao potencial eleitoral que São Paulo e Minas Gerais poderiam angariar durante o alistamento eleitoral, ainda não iniciado quando Dutra lançou-se como candidato à presidência. 
que se realizou nos Campos Eliseos" (OESP, 14/03/45). Isso pode mostrar a preocupação do OESP em fazer de Dutra um símbolo da democracia e de demonstrar a força das adesões a sua candidatura.

A seção a Situação Política daquele dia falou da repercussão da notícia sobre a candidatura de Dutra, na qual se podeler:

Os matutinos aparecem com abundante noticiário sobre o assunto, prendendo a atenção não só nos meios políticos, mas de todas as esferas. Aguardava-se com ansiedade o manifesto que indicaria o nome do ilustre brasileiro para suceder ao Sr. Getúlio Vargas, como Chefe da nação. (OESP, 14/03/45).

Podemos notar que o periódico apresenta a candidatura de Dutra como um acontecimento único, no qual a exaltação ao candidato é evidente. Esta atitude pode ser vista como uma forma de mostrar à sociedade que Dutra reunia em torno de si um apoio amplo e geral, que podia ser presenciado em qualquer lugar do país.

Nesse sentido, a seção a Situação Política, de 12 abril de 1945, fala das "adesões à candidatura de Dutra" e agradece às manifestações de solidariedade, neste ponto é possível notar a influência do jornal, pois este publica alguns telegramas recebidos por Dutra.

Ainda nesta exaltação à imagem de Dutra, o jornal, em 17 abril 1945, publica na seção na Situação Política, o texto intitulado "o General Eurico Gaspar Dutra, resistencia fisica e capacidade de trabalho", que diz:

militar cem por cento, o General Dutra não cuidou somente do aprimoramento intelectual. A guerra exige homens fortes, rijos de alma e corpo. [...] é madrugador, por habito e por gosto. Desde que assumiu a pasta da Guerra, chega ao seu gabinete antes das sete horas.[...] O General Dutra não sabe fazer as coisas pela metade. É exato e completo, mesmo nos assuntos de menor importacia [sic] [...] um repórter que o acompanhou em longa excursão nos transmitiu um depoimento que merece ser divulgado.[...] o General, ocupado da manhã a noite, não apresenta o mínimo sinal e cansaço. Tendo se recolhido tarde, ainda de madrugada reiniciava suas atividades. E no mesmo ritimo [sic], decorreu toda a excursão (OESP, 17/ 04/45).

Desta forma, é possível notar que a tentativa de construção do mito Dutra embasava-se no ideal do homem trabalhador, daquele que não conhece a preguiça ou o cansaço, cujo objetivo maior é o trabalho pelo Brasil. A posição dos diretores d'OESP pode ser observada por meio dos editoriais que o apresentavam como o exemplo a ser seguido, como o verdadeiro homem público e defensor da democracia, além disso, o periódico mostrava a aceitação da campanha por todo o país. 
O Envolvimento do periódico na campanha pró Dutra era tão explícito que foi publicada, no número do dia 20 maio de 1945, uma reportagem sobre Abner Mourão, então diretor do OESP, que se encontrava em Vitória para participar das reuniões do comitê eleitoral de Dutra, dizendo que: “o Dr. Abner Mourão representará, nesse conclave o exmo. General Eurico Gaspar Dutra, candidato das forças políticas nacionais à suprema magistratura do país, para que foi especialmente convidado" (OESP, 20/04/1945). Ou seja, o diretor do jornal era então claramente apresentado como representante de Dutra.

No próximo capítulo tratarei dos aspectos que permearam os editoriais do jornal quanto a sua percepção do Queremismo e da participação política dos trabalhadores.

\section{A Campanha de Dutra e o Queremismo}

Segundo Ferreira, o Queremismo tinha por base a continuidade de Vargas no governo, pois os trabalhadores associavam-na à manutenção dos benefícios, Vargas seria assim visto não apenas como o criador, mas também como guardião dessa legislação.

O Queremismo vinculou-se aos sindicatos e demais setores que queriam a permanência de Getúlio Vargas como chefe da nação, sendo seus momentos mais intensos os meses de julho a agosto, ainda conforme Ferreira:

As mudanças, de julho para agosto, portanto, são significativas. Da simples personalização da política com a palavra de ordem "Queremos Getúlio", o movimento passou a reconhecer a necessidade da própria institucionalização da política, por meio de uma assembléia constituinte. (FERREIRA, 2005, p. 52).

Mas, mesmo com as manifestações políticas, pró candidatura de Vargas, tornando-se mais intensas nos grandes centros, O Estado de S. Paulo não manifestava qualquer notícia sobre tais acontecimentos, o que indica que esta campanha não interessava aos seus diretores ou que eles não queriam prestigiá-la, concedendo-lhe espaço no jornal, uma vez que eram defensores da candidatura de Dutra, então pode-se interpretar que o silêncio, neste caso, foi visto como a melhor opção, uma vez que a oposição sistemática ao movimento era o mesmo que ser opositor a Vargas, o que poderia conferir maior desprestígio à candidatura de Dutra, e o jornal tornara-se, cada vez mais, "cabo eleitoral" do General.

Contudo, o silêncio pelo qual o jornal optara em certo momento tornou-se insustentável e, na primeira vez em que fez referência ao queremismo, este foi 
apresentado como um fato isolado. O título dado à reportagem: "o povo dissolveu um comício da UDN", mostrou que se tratava de manifestações políticas do povo contra a UDN e no corpo da notícia se lia:

O Ministro João Alberto deveria falar hoje aos jornalistas sobre o incidente ocorrido no comício da União Democrática Nacional em Vila Isabel. Devido a incontinência de linguagem dos oradores, que ao invés de fazer propaganda do seu candidato, timbravam em atacar com os mais pesados insultos o presidente Vargas, o povo dissolveu o comício que se realizava naquela localidade (OESP, 7/8/ 1945).

Esta notícia é pode ser vista como uma manifestação queremista, que ocorreu no Rio de J aneiro, contudo, o jornal, não lhe dá grande destaque. A manifestação é apresentada como gratuita por parte do "povo", além disso, não notamos que a notícia não estabelece qualquer ligação com o Queremismo, uma vez que a notícia é mostrada como um incidente político atípico e aproveita para atacar o discurso da UDN que, segundo o texto não apresentou seus candidatos.

Depois desta reportagem o jornal permaneceu 14 dias sem citar qualquer relação de manifestações populares ou de apoio a Vargas.

Mas, no dia 20 de agosto, foram organizados vários comícios pelos queremistas por todo o país, o mais significativo deles foi o realizado no Rio de J aneiro quando, ao final do comício, os manifestantes dirigiram-se ao Palácio da Guanabara para falar com o chefe do Governo e manifestar o seu apoio a sua candidatura. OESP publicou três reportagens falando sobre esse comício Queremista, um dia depois da sua realização.

Ojornal enfatizou aquele ocorrido no Rio de J aneiro, dividindo a cobertura em três partes que citarei a seguir ${ }^{13}$. A primeira leva o título de "comício pró-candidatura Getúlio Vargas", narrando que:

Realizou-se hoje a tarde no Largo da Carioca, o anunciado comício pró-candidatura do Sr. Getulio Vargas a Presidência da República. Perante a Multidão que se reuniu falaram números oradores, todos focalizando a obra realizada pelo Presidente Getulio Vargas. O nome do Chefe do Governo era constantemente aplaudido e foi entre vivas e manifestações calorosas ao Presidente Vargas (OESP, 21/ 8/ 1945).

Nesta reportagem o jornal apresenta praticamente uma nota sobre o ocorrido, sem demonstrar grandes embates políticos, apenas apontando para o prestígio que Vargas possuía, não notamos nessa narrativa a presença de trabalhadores, ou mesmo a indicação de tratar-se de uma manifestação de cunho popular.

13 As notícias foram escritas no dia 20 e publicadas no dia 21 de agosto. 
Além disso, a manifestação é apresentada no corpo do texto como "o anunciado comício", dado curioso uma vez n’O Estado de S. Paulo, não houve qualquer notícia anterior sobre os comícios queremistas.

Já a outra reportagem possui o seguinte título "manifestação popular no Guanabara", descrevendo que:

Conduzido cartazes e dísticos, a massa popular chegou à residência presidencial às 20 horas e meia e erguendo vivas prolongadas. $\mathrm{O}$ oficial de serviço o capitão-aviador Carlos Alberto Lopes, veio ao jardim receber o povo. Fizeram então um apelo para que pedisse ao Presidente da República chegar a varanda, pois desejavam se desobrigar da missão que os oradores do comício lhes haviam delegado. Enquanto o Capitão-aviador Carlos Alberto voltou para a secretaria a fim de falar ao Sr. Getulio Vargas, os aplausos e as palmas aumentaram de intensidade (OESP, 21/8/ 1945).

Aqui o jornal faz referência ao desdobramento do comício, que acabou por chegar ao Palácio Guanabara, informando se tratar de um movimento popular, dado que foi suprimido na primeira reportagem. Além disso, podemos notar que o jornal mostra que tal manifestação deu-se por que os oradores que "delegaram" tal função à massa popular, o que pode indicar que o jornal utilizava essa informação para demonstrar que a população era incentivada a realizar tais atos, uma vez que o jornal até então havia citado apenas uma vez algo relacionado às manifestações populares ocorridas no dia 7 de agosto.

Até aquele momento o jornal procurava por todos os meios não legitimar o Queremismo, pois o crescimento do movimento ameaçava a candidatura de Dutra em prol da candidatura de Vargas.

Já a última parte da reportagem, com o título "o chefe do governo recebe o povo", faz-se menção à recepção e diálogo de Vargas com os manifestantes.

[...] em rápidas palavras agradeceu a homenagem, recordando que sempre procurara servir os interesses do povo. Já fazia 15 anos que governava o Brasil, então - perguntou - os manifestantes não achavam que tinha o direito de descansar. A massa popular interrompeu bradando. - "não, não! V. Exa. Não pode nos abandonar. O senhor Getulio Vargas prosseguiu e disse que não pretendia abandona-los, mas apenas descer as escadas do palácio para viver no meio do povo, de onde saíra, e que, juntos haviam de achar o caminho que os levaria a felicidade do Brasil. As afirmações do Chefe do Governo eram interrompidas de palmas e aplausos (OESP, 21/8/1945).

Aqui o jornal enfatiza a postura de Vargas em afirmar que não seria candidato à presidência, pois pretendia descansar. Outro ponto interessante, destacado nas falas 
de Vargas, era sua rememoração dos 15 anos de governo. Governo este que trouxe vários benefícios sociais e que elevou o carisma de Vargas e favoreceu o surgimento do Queremismo. Assim, as relações d'OESP com o Queremismo nunca foram de associação direta, uma vez que ambos, jornal e movimento, possuíam objetivos bem diferentes em relação à sucessão presidencial. Por outro lado, o jornal não podia criticar abertamente o movimento, sob pena tanto de atrair para o seu candidato a antipatia dessa parcela da população que apoiava Vargas quanto de confundir-se com a postura da UDN que há tempos vinham criticando o governo.

Quanto ao Queremismo, o jornal publicou ainda uma entrevista com Segadas Viana ${ }^{14 \cdot}$, sobre a condição do PTB em relação à candidatura de Vargas.

\begin{abstract}
-mas não é verdade que o Sr. Getulio Vargas será o candidato ao Partido Trabalhista? - não posso falar em nome do partido. O presidente Getulio Vargas é muito querido por todos os trabalhadores, por todo o povo. Sua obra político-social é indiscutível candidato ou não, na presidência da Republica ou como simples cidadão, ele será sempre o mais querido amigo dos trabalhadores que tem coragem de afirmar que não conhecem a palavra ingratidão com a sua orientação social marcharam unidos os proletários manuais e intelectuais, porque essa orientação sempre foi leal e patriótica. (OESP, 28/ 8/ 1945).
\end{abstract}

Nesta entrevista, Segadas Viana toca num assunto muito enfatizado pelos queremistas: os benefícios sociais, que também passaram a ser utilizadas na campanha de Dutra. Além disso, é possível notar que o PTB não se manifesta nem contrário e nem a favor da candidatura de Vargas, mas declara apoio dos trabalhadores para qualquer rumo que Vargas seguir.

Assim, para o jornal, o Queremismo representava uma relação de forças que poderia fazer a diferença na disputa eleitoral. Mas como trazer o apoio destes trabalhadores para a candidatura de Dutra? Uma forma possível seria apresentar Dutra como o candidato mantenedor das políticas sociais implementadas por Vargas, além de buscar o apoio do PTB, ou de parte dele.

Durante todo o movimento Queremista notamos que OESP não realizou campanha pró candidatura de Vargas. Contudo, ao longo do movimento aumentaram as reportagens que colocavam o PTB em certa evidência, além de outras que abordavam justamente questões trabalhistas que, de acordo com o jornal, constavam no programa de Dutra, buscando afirmar Dutra como sendo candidato dos trabalhistas também.

Desta forma, o que proponho como explicação é que o jornal não se manifestou quanto à dimensão do Queremismo, mas as reportagens de aproximação

14 Um dos fundadores do Partido Trabalhista Brasileiro. 
entre Dutra e a causa trabalhista indicam que o eleitorado pró Vargas não foi totalmente deixado de lado pelo Estadão. Nesse caso pode-se questionar o motivo do Queremismo não ter sido amplamente divulgado pelo jornal.

A resposta para essa questão passa pela situação da candidatura de Dutra, naquele momento, em São Paulo e nos outros Estados. Segundo Ferreira:

Dias antes do comício, nas sedes do PSD em São Paulo e no Recife, a Propaganda eleitoral de Dutra foi substituída pela de Vargas. Diversas alas do PSD declararam apoio político ao presidente. A candidatura de Dutra, até aquele momento sem empolgação alguma, ameaçava esvaziar-se por completo (FERREIRA, 2005, p. 47).

Mesmo com a ampla difusão de apoio, a candidatura de Dutra estava enfraquecida pelo Queremismo, desta forma, a busca por apoio desta parte do eleitorado - "os trabalhadores" - era algo fundamental para se conseguir a vitória no dia 2 de dezembro, pois tanto a UDN quanto o PSD disputavam os votos das classes médias e altas e os trabalhadores poderiam ser o elemento de desempate nesta balança.

Assim, o jornal não aderiu ao Queremismo e defendeu amplamente a candidatura de Dutra como "representante da maioria", por isso começou a apresentar questões sociais para serem discutidas, no dia 4 de agosto apareceu na seção a Situação Política uma reportagem com o título "Reivindicações dos trabalhistas cabem nos quadros do PSD" esta talvez seja uma tentativa de aproximar a candidatura de Dutra do trabalhismo, pois a manutenção de Vargas, defendida pelo Queremismo, possuía como principal argumento a manutenção dos benefícios sociais.

\section{O Estado de S. Paulo e o PTB paranaense}

Pelo exposto até aqui, percebe-se que a aproximação com o PTB é de extrema importância para a campanha de Dutra. Mas como conseguir apoio do PTB sendo que em São Paulo este partido, em sua maioria, apoiava a candidatura de Vargas?

A resposta vem do estado vizinho, o Paraná. Para manifestar apoio a Dutra não importa de qual sede estadual do PTB ele viria, o importante seria conseguir que um diretório do PTB se manifestasse como "pró Dutra". Além do mais, o presidente da comissão nacional do PTB, Luis Augusto França, defendia a candidatura de Dutra, deparando-se, mais tarde, com outra vertente, liderada por Segadas Viana, que convocou uma nova convenção nacional, mudando todo o quadro de líderes do PTB, situação que dificultava a vinculação de Dutra ao PTB, mas mesmo assim o jornal publicou: 
Tendo dado entrada ao seu pedido de registro no Tribunal Superior Eleitoral, o Partido Trabalhista Brasileiro, por intermédio de seu presidente Sr. Luis Augusto França, reinteirou a sua adesão à candidatura ao Sr. Eurico Dutra. (OESP, 19/ 08/1945).

Segundo D’Araujo (1996, p. 28-30):

Munido dos estatutos, de um programa e de todas as exigências legais, no dia 17 de agosto de 1945, Luís Augusto França requereu ao TSE o registro do PTB. A essa altura o partido possuía um Diretório Nacional Provisório composto de 30 sindicalistas, à frente dos quais estava o próprio Luís Augusto França, como presidente [...] Enquanto se providenciavam o registro e a organização do partido, Luís Augusto França seguia para o Paraná a fim de promover a candidatura presidencial do general Dutra, lançada pelo PSD.

Esta viagem de Luís Augusto França ao Paraná é importante para compreender-se o porquê da adesão do PTB paranaense à candidatura de Dutra, situação que será muito explorado pelo OESP que lhe conferirá legitimidade aos PTB paranaense como único e legitimo.

Em entrevista ao jornal OESP, o presidente do PTB Luís Augusto França $^{15}$ disse:

Acabo de chegar de Curitiba, aonde fui assistir a convenção trabalhista promovida pela União dos trabalhadores do Paraná, a fim de ingressar nos quadros do P.T.B. que, como se sabe, apoiará a candidatura Gaspar Dutra a Presidência da República. Os operários hoje estão organizando e na pior das hipóteses teremos $80 \%$ da massa trabalhadora do Paraná (OESP, 11/ 07/ 1945).

Com as disputas políticas em torno do PTB, e o seu primeiro presidente apoiando o PTB do Paraná pró candidatura Dutra, o jornal utilizará essa posição de forma clara. No mesmo dia 11, se pode ler:

\begin{abstract}
A União Trabalhista no Paraná, reunindo cerca de 50.000 proletários, realizou em Curitiba, no último domingo segundo minucioso noticiário publicado pelo "o Estado de S. Paulo". Uma convenção de alta importância política. Essa convenção resolveu apoiar o nome do General Eurico Gaspar Dutra à Presidência da Republica e o fez de modo mais significativo: depois de equacionar o valor do candidato com os legítimos interesses dos trabalhadores brasileiros. [...] o líder trabalhista Luis Augusto França, presidente do Partido Trabalhista Brasileiro com o vivo apoio da assembléia, assim positivou as razões da solidariedade a candidatura do eminente nacional General Eurico Gaspar Dutra (OESP, 11/ 07/ 1945).
\end{abstract}

15 Que permaneceu no cargo até a convenção de 25 de agosto a 5 de setembro, quando a presidência foi ocupada por Paulo Beata Neves. 
Aqui se nota que a quantidade de operários presentes, citada pelo jornal, pode ser uma forma de comover os trabalhadores a aderirem à candidatura de Dutra, uma vez que a reportagem apresenta Dutra como "candidato com os legítimos interesses dos trabalhadores brasileiros", e nesse caso o jornal não fala voltado para o Paraná, mas para os trabalhadores brasileiros, o que evidencia a preocupação uma preocupação maior com o eleitorado nacional. Toda e qualquer forma de ligar a imagem do PTB à candidatura de Dutra não deveria ser desconsiderada e sim explorada, pois gerar-lhe votos e o OESP mostrava-se cada vez mais empenhado na corrida presidencial.

Outra questão assinalável é que o jornal não deu destaque ao fato de que, como aponta Ferreira, "às 18 horas, de 20 de agosto, uma multidão tomou conta do Largo da Carioca, no Rio de J aneiro para participar do primeiro comício queremista" (FERREIRA, 2005, p. 44).

A falta de interesse, por parte do jornal, na cobertura do comício Queremista é um dado interessante, haja vista que no dia 22 de agosto, o jornal deu sinais de que o PTB, em âmbito nacional, não possuía nada definido em relação a sucessão presidencial.

Assim, o jornal publicou um comunicado do Partido Trabalhista na Situação Política dizendo que: “O P.T.B. ainda não tem candidato à Presidência da República, pois espera o resultado da convenção que se realizará no dia 2 de setembro na Capital Federal”. (OESP, 22/8/1945). Desta forma a posição do Partido é claramente apresentada no jornal, mas isso não mudará sua relação com PTB paranaense.

O apoio do PTB paranaense ainda será amplamente enfatizado para caracterizar Dutra como candidato dos trabalhistas, a exemplo desta matéria intitulada “O P.T.B. e a candidatura de Dutra”, na qual se lê:

\begin{abstract}
Esteve em conferência com o General Dutra, na sede do P.S.D. o Sr. Milton Viana, delegado da seção do P.T.B. paranaense. O Sr. Milton Viana expõs [sic] ao candidato das forças majoritárias à presidência da Republica o que ocorreu em Curitiba por ocasião da convenção trabalhista ali reunida há um mês.[...] "A nossa convenção foi a primeira de todas até agora realizadas pelo Partido Trabalhista Brasileiro. Reunimos todas as expressões mais significativas dos trabalhadores do Paraná e tivemos a iniciativa, no Partido de adotar a candidatura do General Eurico Gaspar Dutra à suprema magistratura do país. (OESP, 25/8/ 1945).
\end{abstract}

Nesta reportagem podemos notar a busca de legitimidade à convenção paranaense, principalmente quando se destaca: "A nossa convenção foi a primeira de todas até agora realizada pelo Partido Trabalhista Brasileiro" esta legitimação é 
necessária para mostrar que o PTB está com Dutra desde o início, mesmo sendo apenas o PTB do Paraná.

O apoio do PTB paranaense é claro nos editoriais, mas o interessante é a atitude do jornal quando o PTB adia a sua confirmação sobre a decisão de qual candidato seria indicado pelo Partido, notando-se a indignação dos editores quando, no dia 26 e agosto, é publicada a seguinte reportagem:

Podemos confirmar, com absoluta segurança, diz a nossa Sucursal do Rio, a notícia enviada sobre a realização, no dia 26 , da anunciada Convenção do Partido Trabalhista Brasileiro. Essa cerimônia, que deveria ser realizar-se no Teatro Municipal com representação de todos os Estados Brasileiros, foi adiada para o dia 2, e depois para o dia 8 de setembro. A esse tempo estariam já desincompatibilizados todos os prováveis candidatos que exercem cargos oficiais. Ao partido, mal articulado, falta um pouco de disciplina vital nas agremiações políticas (OESP, 26/8/ 1945).

A espera do PTB é vista pelo jornal como uma falta de articulação e disciplina, pois a direção do partido atrasou a convenção, esperando uma possível decisão de Vargas concorrer à presidência.

Ainda na mesma reportagem há exaltação do PTB do Paraná, que é considerado pelo jornal um "núcleo perfeitamente coeso, constituído" o que indica que jornal conta com o apoio do PTB paranaense para a disputa do pleito como uma força política que irá contribuir para a candidatura de Dutra. E, continuando, a reportagem mostra porque elogia o PTB paranaense.

São visíveis as cisões e dissidências. Alias dentro do P.T.B. só havia um núcleo perfeitamente coeso, constituído fora dos sindicatos e com expressão eleitoral - o do Paraná. Esse não recua, nem de seu propósito, nem de seu candidato. A delegação que se encontra no Rio declarou, categoricamente, que os proletários paranaenses e todos os componentes da poderosa célula, que, de fato organizou o partido que se desfaz manterão a candidatura do General Eurico Dutra. (OESP, 26/8/ 1945).

O Uso do PTB paranaense nas reportagens do jornal procura demonstrar aos leitores que Dutra possui apoio desse núcleo do Partido que, de acordo com o veículo, representa sua parte "coesa”, e confiável, pois este não abandonou a candidatura de Dutra, enfatizando ainda que nesse núcleo teria se originado o partido.

No dia 30 de agosto, o jornal publica nova reportagem, falando do congresso do PTB que estava se realizando no Rio de J aneiro, e ao longo da reportagem a imagem do Núcleo paranaense é mais uma vez utilizada. Segundo o jornal: 
Logo na seção preliminar do congresso do Partido Trabalhista no Rio, a delegação do Paraná chefiada pelo Dr. Milton Viana propôs a adoção da candidatura nacional do General Eurico Gaspar Dutra, já lançada pela convenção regional de Curitiba. Esta leal e coerente atitude, em correspondência com os mais altos interesses do Brasil, causou grande impressão. Tudo indica que o Partido Trabalhista, por todos os motivos, inclusive os da sua própria sobrevivência, chegará unanimemente a essa candidatura (OESP, 30/8/ 1945).

Neste trecho é interessante notar que o PTB paranaense é classificado como "leal" e por possuir "correspondência” com a candidatura de Dutra, logo, Dutra também poderia ser considerado "leal" pelos trabalhadores.

Outro ponto interessante é a afirmação de que, caso o PTB não apoiasse a candidatura de Dutra, o partido corria o risco de acabar. Para compreender esta afirmação é preciso lembrar que a lei eleitoral exigia a formação de partidos nacionais e para tal eram necessárias dez mil assinaturas, em cinco estados diferentes, o que o PTB não conseguiu, pois a sua sede teria sido invadida e as listas roubadas. Para solucionar esse problema, segundo Gomes, "novas listas foram 'tiradas' do PSD" (GOMES, 2002, p. 4).

A adesão à candidatura de Dutra estaria então quase certa, uma vez que o jornal estava ligado ao PSD, e estas informações provavelmente estariam a sua disposição, o que poderia explicar tal afirmação. Além do mais, é possível notar que a notícia possui um tom de quase adesão do partido graças ao discurso do líder paranaense, o que fortalece a visão de núcleo "sério" do PTB paranaense.

A partir de então se seguiram mais quatro dias da convenção nacional do PTB, o período de desincompatibilização chegou ao fim e Vargas, não a tendo realizado, não poderia concorrer ao pleito de 2 de dezembro. Em relação a isso, o jornal publica uma extensa reportagem, da qual cito uma longa parte, por considerá-la esclarecedora a essa análise:

2 ${ }^{\mathbf{a}}$ indicação - consequentemente, considerando que o Presidente Getulio Vargas, no seu memorável discurso de 1ํㅡㄹ de maio do corrente ano, falando aos trabalhadores do Brasil, declarou que o nome do General Eurico Gaspar Dutra se recomendava à consideração do povo, como candidato das forças majoritárias e como homem público de expressão moral inatacável, capaz de garantir à frente dos destinos da pátria, o prosseguimento da obra social e política já iniciada; considerando que, reinteradas vezes, por igual modo, o candidato General Eurico Gaspar Dutra terá assumido compromissos formais de manter, consolidar e desdobrar essa obra, relativamente ao amparo que desejamos aos trabalhadores de todas as categorias profissionais; considerando que a palavra empenhada do General Eurico Gaspar Dutra é uma segurança de que serão realizados as aspirações contidas no programa do Partido Trabalhista Brasileiro; e considerando, finalmente que Sua Exellencia, pela situação de General 
do Exército, organizador da FEB, é neste contexto indeciso para o mundo, o homem indicado e capaz de garantir ordem interna e a soberana nacional. INDICAMOS a ratificação do nome do General Eurico Gaspar Dutra como candidato do Partido Trabalhista Brasileiro à presidência da República, de acordo com as resoluções já tomadas na Convenção do Estado do Paraná, a que estiveram presentes representações autorizadas dos Estados da Bahia e de Santa Catarina, bem como o Presidente da Comissão Executiva Provisória do Diretório Central, todos unanimes em aplaudir as deliberações tomadas naquela convenção, em torno do nome do eminente soldado". (OESP, 4/9/1945).

A adesão à candidatura de Dutra é finalmente aceita em nível nacional, mas o jornal faz ainda questão de mostrar que tal adesão já havia sido feita na convenção do Paraná, e agora que o Queremismo já havia chegado ao seu fim e Vargas definitivamente não seria candidato, os diretórios estaduais poderiam concentrar-se na candidatura de Dutra e buscar apoio nos meios operários.

Pode-se então conjecturar que a aceitação da candidatura de Dutra pelo PTB só se deu porque Getúlio Vargas não seria candidato, tanto que esta resolução, publicada pelo jornal, é de dois dias depois do período de desincompatibilização, ou seja, o PTB em nível nacional optou por não pronunciar-se até o dia 2 de setembro.

\section{Os Desdobramentos do Pleito de 1945}

Na disputa à presidência da República figuraram o General Eurico Gaspar Dutra (PSD-PTB), o Brigadeiro Eduardo Gomes (UDN) , e o Engenheiro Yedo Fiúza (PCB) como candidatos.

A candidatura de Eduardo Gomes era a que aparentemente mais empolgava, seja pelo apoio que lhe garantiam os meios de comunicação, seja simplesmente pelo anti-Varguismo, que unia várias tendências de oposição, embora não possuísse apelo popular.

Já a candidatura de Dutra não possuía mesma empolgação que do Brigadeiro, embora Dutra contasse com ampla adesão dos interventores estaduais, que em boa parte compunham os quadros do PSD.

Segundo Gomes, Com a proximidade das eleições a vitória era incerta, mas as maiores chances eram de Eduardo Gomes, mesmo que Dutra estivesse coligado com o PTB, isso não lhe garantia adesão dos trabalhadores, principalmente pelo silêncio de Vargas, o grande líder trabalhista. Contudo, o silêncio foi quebrado e "o apoio de Vargas ao PSD, através do conhecido 'ele disse: vote em Dutra', foi decisivo" (GOMES, 2002, p.4). Esse apoio foi uma dos grandes trunfos de Dutra, uma vez que o carisma de 
Vargas e o apelo político dos líderes petebistas, garantiram-lhe a maior percentual de votos angariado em uma eleição presidencial até aquele momento. Segundo Ferreira:

Nas eleições de 2 de dezembro, Eurico Dutra, surpreendentemente e contrariando todos os prognósticos, obteve 55,39\% dos votos, com uma votação maciça em São Paulo, Minas Gerais e Rio Grande do Sul; Eduardo Gomes conseguiu 35,74\% dos votos; enquanto Yedo Fiúza amealhou 9,7\% (FERREIRA, 2005, p.87).

O processo eleitoral garantiu a volta ao regime democrático que, após 15 anos, passou a contar com um novo elemento político, que a partir daquele momento não poderia mais ser desconsiderado: os Trabalhadores.

\section{Considerações Finais}

As eleições de 2 de dezembro de 1945, foram muito significativas , pois o Brasil não realizava uma eleição direta para presidente desde 1929, quando Júlio Prestes foi eleito, mas não empossado, devido ao golpe de 1930, que entregou a Vargas o comando do governo provisório.

Esta eleição foi significativa ainda porque marcou a efetivação da importância dos trabalhadores no cenário político nacional, uma vez que antes de 1945 eles não eram os principais votantes, e as eleições, ao longo da Primeira República, não eram exatamente uma manifestação democrática, pois o voto não era secreto e as eleições eram frequentemente fraudadas.

Desta forma, este trabalho buscou analisar questões que surgiram naquele contexto, uma vez que as eleições de 1945 foram marcadas pela presença deste novo agente político. Por isso me preocupei em apresentar as relações entre o jornal O Estado de S. Paulo, o PTB e o Queremismo, caracterizando uma opção política principalmente por parte do OESP, que buscou criar para Dutra a imagem de um líder democrata, que iria manter o país no rumo da legalidade e da ordem, assim como fizera liderando o Brasil na Guerra além de, mais tarde, vincular Dutra à manutenção das políticas sociais varguistas. Além disso, o jornal não manifestou sua opinião em relação ao Queremismo, e apenas noticiou alguns acontecimentos procurando manter-se, em relação a esse movimento, no terreno da "neutralidade".

A principal questão deste trabalho foi explicar o motivo e as formas pelas quais o jornal procurou demonstrar o apoio do PTB a Dutra como candidato dos trabalhistas. Contudo, o que mais chamou atenção foi a imagem veiculada do PTB paranaense, que manifestara sua opção por Dutra, fato muito bem explorado pelo jornal, que inclusive 
defendeu a idéia de que este apoio foi de extrema importância para a decisão do PTB em nível nacional na adesão à candidatura do General.

Este trabalho abre uma porta que permite alguns questionamentos como, por exemplo, qual a importância do PTB paranaense no cenário político de 1945? Como era a sua organização? Quais eram as influências de seus líderes? Como este partido se comportou ao longo de seus vinte anos? Como é sabido, o OESP foi restituído aos seus donos, surgindo aí uma nova problemática: qual foi o comportamento "dos Mesquita" em relação ao governo Dutra? Estas são questões a serem analisadas no futuro e que poderão render algumas páginas de discussões em outro trabalho.

Uma pergunta que me fiz logo que iniciei este estudo foi sobre o tipo de notícia a ser apresentada por um jornal de grande circulação em relação ao PTB? E se por acaso esses jornais teriam deixado de lado a candidatura de Dutra, em detrimento da possível candidatura de Vargas?

As respostas que encontrei são muito interessantes, uma vez que o OESP não noticiava muita coisa sobre o PTB até o momento em que o Queremismo mostrou sua força e a de seus aliados, os trabalhadores, e aí o OESP passou a amparar-se e a dar maior importância na cobertura jornalística ao PTB paranaense.

Quanto ao esvaziamento da campanha de Dutra pelos grandes periódicos, esta não ocorreu no OESP, na verdade constatou-se o contrário, pois a campanha pró Dutra ocorreu desde a pré-candidatura até a desincompatibilização, pode-se dizer que o jornal mostrou-se "dutrista" o tempo todo.

Portanto, acredito que este trabalho responde algumas questões e levanta outras tantas, mas uma coisa pode-se afirmar: a existência de uma força política que os trabalhadores conseguiram construir ao longo dos quinze anos do primeiro Governo Vargas e a sua importância no pleito Presidencial de 1945.

\section{Documentos Consultados}

O Estado de S. Paulo. São Paulo, de 3/ 1/ 1945 a 21/ 9/ 1945. Acervo do CDPH/ UEL.

\section{Referências}

BRAGA, J osé Luiz. “Questões metodológicas na leitura de um jornal”. In: PORTO, Sérgio D. (Org.). OJ ornal: da forma ao sentido. 2. ed. Brasília: Ed. UNB, 2002. p. 321334.

CAPELATO, Maria Helena Rolim. Os arautos do liberalismo imprensa paulista 19201945. São Paulo: Brasiliense, 1989.

. A imprensa na história do Brasil. São Paulo: Contexto/EDUSP, 1994. 
. O Estado Novo: o que trouxe de novo? In: FERREIRA, J orge; DELGADO, Lucilia de Almeida N. (Org.). O Brasil republicano 2: o tempo no nacional-estatismo. Rio deJ aneiro: Civilização Brasileira, 2006, p. 107-143.

CAPELATO, Maria Helena Rolim; PRADO, Maria Lígia. O bravo matutino: Imprensa e ideologia: o jornal o Estado de S. Paulo. São Paulo: Alfa-Omega, 1980.

D'ARAUJ O, Maria Celina. Sindicatos, carisma e poder: o PTB de 1945-65. Rio de J aneiro: Editora da Fundação Getúlio Vargas, 1996, p. 21-33.

FERREIRA, J orge. O imaginário trabalhista: getulismo, PTB e cultura política popular 1945-1964. Rio de J aneiro: Civilização Brasileira, 2005, 21-89.

GOMES, Angela Maria de Castro. A Invenção do Trabalhismo. São Paulo: Vértice, 1988, p. 189-329.

GOMES, Angela Maria de Castro; D’ARAÚJ O, Maria Celina. Getulismo e Trabalhismo. São Paulo: Ática, 1989.

Uma breve história do PTB. Rio de J aneiro: CPDOC, 2002. Palestra no I Curso de Formação e Capacitação Política, realizado na Sede do PTB. São Paulo.

PANDOLFI, Dulce Chaves. Os anos de 1930: as incertezas do regime. In: FERREIRA, J orge; DELGADO, Lucilia de Almeida N. (Org.). O Brasil republicano 2: o tempo no nacional-estatismo. Rio de J aneiro: civilização brasileira, 2006. p. 13-37.

Colaboração recebida em 16/ 03/ 2011 e aprovada em 18/ 10/2011. 